\title{
Study on the Curriculum Reform of Local Agricultural Colleges and Universities in the Era of Network Curriculum
}

\author{
Xinxin Mao \\ Jilin Agricultural University, Changchun 130118, China
}

\begin{abstract}
With the rapid development of modern computer network technology, its application is more and more widely, and gradually penetrate into the various parts of education and teaching. Apply the network technology to teaching, which can not only make up for the defects and deficiencies in the traditional teaching, but also provide continuing education space for students and even the educators in the whole society, and implement the concept of lifelong learning, especially for the local agricultural College students. In consequence, to achieve the network assisted teaching as soon as possible is a necessary way to explore the new teaching mode that obtains two-way benefits in the quality of education and education cost. Aiming at the deficiency of traditional teaching, this paper develops the network teaching system of agricultural Colleges and universities. The system, based on Internet network, provides the teaching environment and teaching resources which are necessary for network teaching for both teachers and students. First of all, this paper elaborates the auxiliary teaching role of computer network technology in the teaching, and then combine with the specific application, specifically analyze the users' needs, and put forward the development scheme and the realizing way of agricultural teaching and network teaching system. This system adopts three layers' system structure, and pays attention to the good expansibility, using modular design method to divide it into teacher management module and student management module, and select object-oriented, easily expanding ASP programming language environment for the development and implementation.
\end{abstract}

Keywords: curriculum reform; local agricultural Colleges and universities; era of network curriculum.

\section{Introduction}

China's local agricultural universities are the Colleges and universities of our country that have stronger professional specialty. There is a certain difference in the construction of schools, professional settings, students' origin and other problems of China's local agricultural universities compared with comprehensive Colleges and universities. Whereas, with the continuous development of the economy of our country, the demand for talents becomes larger and larger. The school scale and the scale of enrollment of Colleges and universities continues is gradually growing [1-2]. In the meanwhile, professional categories are also in increasing, making a trend of difference gradually narrowing. The task of network teaching is not simply to publish the teaching resources on the Internet, but also the exchange and communication between students and teachers, students and students. And in the network teaching, teachers and students are separated in space, not face to face, so the exchange and communication between each other is even more necessary. In addition, some key steps of teaching in traditional agriculture in the teaching link, such as assignments, exams, question answering and so on [3]. These all should be reflected in the network teaching system, while the current existing network technology does not provide the tools we need. In consequence, the development of network teaching system is very necessary for the teaching career development in agricultural Colleges and universities. 


\section{Related Technologies of the Network Course Teaching System in Local Agricultural Colleges}

\subsection{Network Structure Model}

The system adopts Browser/Web Server/DBMS Sever three layers' structure mode. According to the three layers' structure mode, the system is divided into user interface, application program and data processing module. The user interface module realizes the human-computer interaction between the system and the user; the reference program module realizes the system application logic processing; the data processing module realizes the management function of the database access [4]. In this mode, the interface of the user in the client are not together with the application procedure of the system. Thus the user interface, the application logic processing, and data management are totally separated.

The three layers' structure is a developing trend of the application software technology of computer network. It is different from the previous traditional client / server structure. It has the following two advantages. First of all, the use is simple. Users access the page through the use of a simple browser. With the click of a mouse, it will be able to access the voice, image, text, video, and database information, which is especially for the people who are non-computer professional. Secondly, it is easy to maintain. Because it only needs to update the server side of the software, the cost and workload of the maintenance system and upgrade is reduced.

\subsection{ASP Technology}

ASP (Active Server Pages) is the Web application development technology launched by Microsoft in November 1996. ASP is neither a development language nor a tool for development. But in a new generation of dynamic, interactive network application provides a method and technology. Its main feature is that a file and script, based on standard, are organically combined together, and form a dynamic web application server to run on, and according to user requirements to produce standard page to the client browser.

\section{Demand Analysis and Design of the Network Teaching System of Local Agricultural Colleges and Universities}

\subsection{Demand Analysis}

Agricultural Colleges and universities mainly take cultivating agricultural talents as the main task. After graduation, the majority of students are committed to engaging in agricultural development, rural construction and other work, so they need to have a strong body. Therefore, the local agricultural College curriculum is supposed to give full consideration to the problem in the content selection [5]. In improving the students' skills, at the same time, strengthen the training of students' physical quality; when opening a project, according to the specific circumstances, add some sports that are closely related to agricultural development, such as wilderness survival, orienteering, mountain climbing, cross-country running motion and so on.

\subsection{Overall Demand}

Development of the system emphasizes combination of both the "teaching" and "learning", so as to meet the needs of the teachers "teaching", but also to meet the learning style of students. The structure of the system divided modules based on the function of module that the user's need to realize, and the content of the system refers to a simple web page to maintain independence. The system consists of three parts: teacher management, student management and system analysis module. The overall structure of the system is shown in Figure 1. 


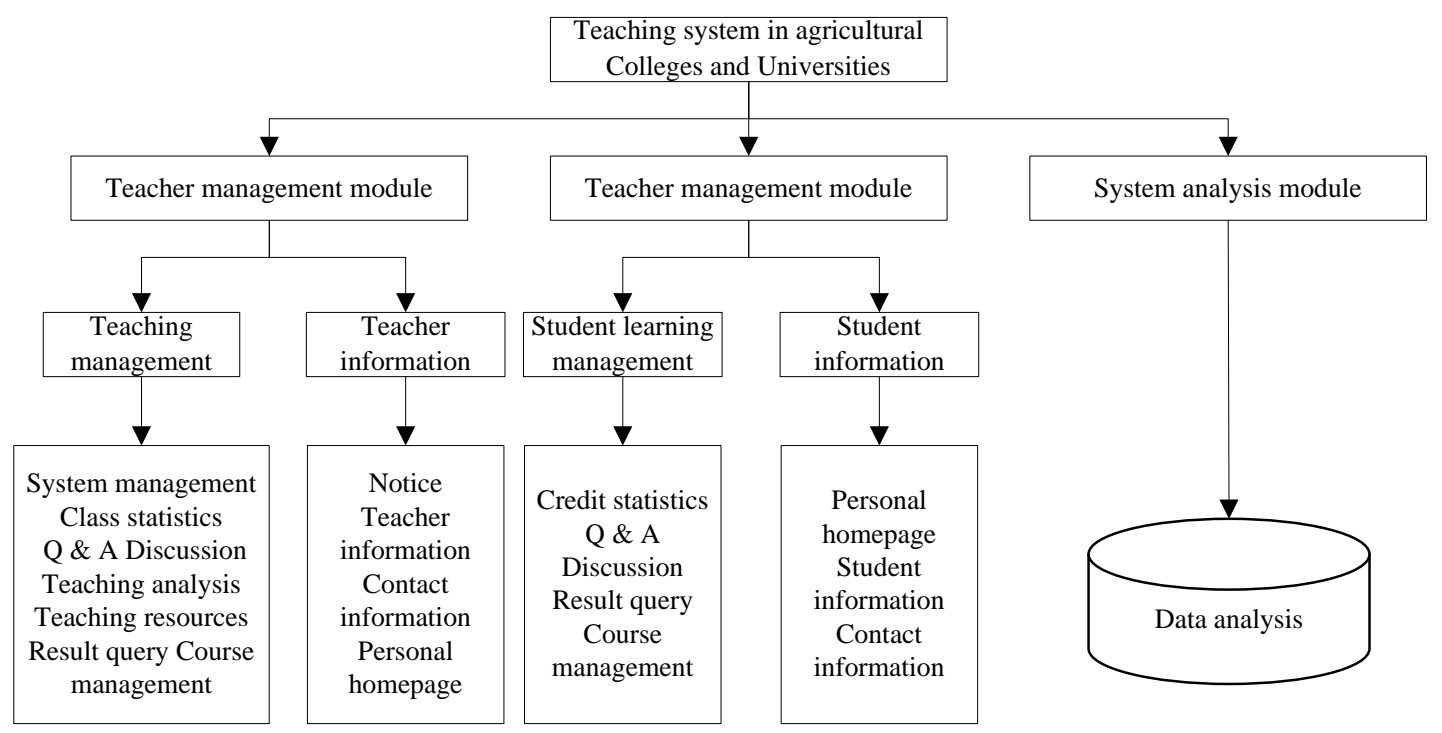

Figure 1 The overall structure diagram

\subsection{Key Point of the Design}

Compared to the traditional teaching, the teacher disappeared, the book into a computer, students' stealth, all courses have a good interaction and controllability. The important influence factors of interaction and controllability are the quality of network teaching and the key problems of students' adult education. Continuous interaction and real-time synchronous interaction can immediately for students to solve problems, for students, teachers and experts of the direct answer to a problem, students between the moment, a question discussion, exchange of ideas and evocative, but this is easy to damage the class, the students focus, from the interactive process of teaching content, the depth of thinking is not enough; and not a real-time interaction can remedy this defect, learners can be more in-depth thinking and the core problem, teachers and experts will have plenty of time to think about to give the appropriate answer.

Network course teaching content should not only follow the general rules. Its value lies in the teaching and learning of knowledge, providing a good carrier to achieve effective learning, which is because of the value of reflected by the combination of teaching content with the network. Some scholars confirmed that the environment of multimedia meaning stimulus and expressing method in life can make the learner to stud in the media [6]. Hypertext, hypermedia, non-linear multimedia teaching content organization can in great extent to prevent the loss of students, provide timely technical support teaching: teaching content, characteristics of teaching media, which are in line with the students' cognitive process, lightening the burden of the students' cognition.

\section{Realization of the Network Teaching System of Local Agricultural Colleges and Universities}

\subsection{Realization of Main Function Module}

The flow chart of the system is shown in Figure 2. When the user input user name and password and enter into the platform, the first thing is to make session object identification. If the session is empty, indicating that the user does not log in or there is error in user name or password input, and then the system will automatically jump back to the log-in page and prompt the user to re-input the user name and password [7]. After the success of the user log-in, the system will judge on the user and assign different permissions so that students can enter the student's operation page, and the teacher to enter the teacher's operation page. This permission is stored in Session, existing in a session of the life cycle. 


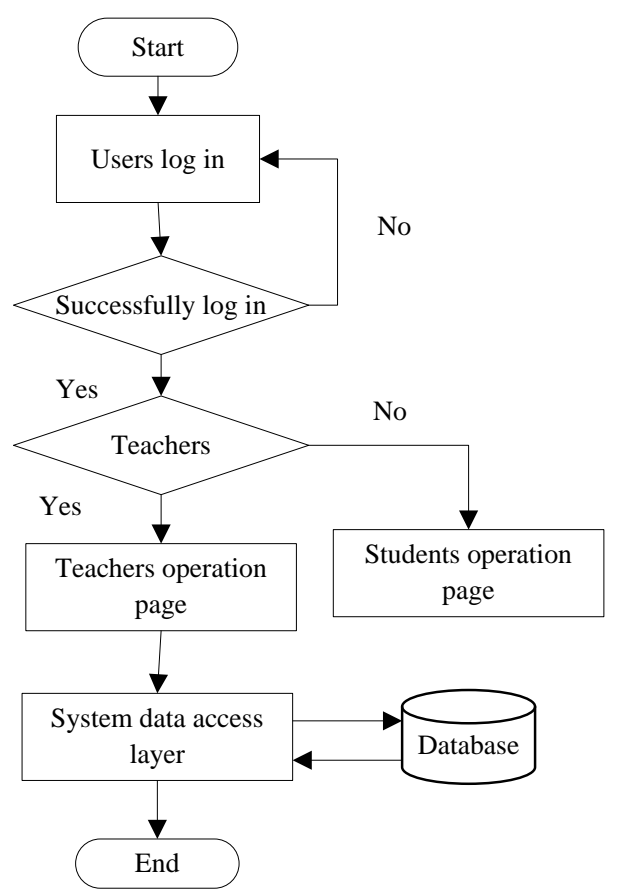

\subsection{Teacher Information Module}

Figure 2 System flow chart

The system administrator has the authority to manage the teacher user. His operation is mainly proceeding add, delete, change, and check on the database related to teachers in the database.

The main job of this function module is to show the teacher's related information to the students. Each teacher's information is corresponding to a record in the database. Teacher's information in the table is the main information related to the introduction of ID, name, research field, the title of a technical post, telephone, Emall, address, zip code and teachers' introduction and so on, in which teachers' ID is the primary key, with uniqueness. After legal users entering the page, the system will query in the database based on the user query ID, and the corresponding teacher information is extracted and displayed on the page.

\subsection{Student Learning Management Module}

In this paper, the students' score query and Q \& A discussion part of agricultural Colleges are taken as example to discuss the module. The main function of this module is to students themselves checking their scores, as well as the analysis of their achievements according to the score standard. Transcripts using Excel table format, teachers uploaded the students' exam scores to the server after the summary, so students cannot only open it online, but also download to view.

This module is a fully open module, candidates can take the test at any time, no longer limited by the time. Test methods refer to the administrator uploads this semester's examination papers to the module, which can be divided into A, B, C, D and other papers with similar difficulty, and students can randomly select.

Test method: when the student legally logs in, they can choose to enter the examination room. After entering the test, they can enter the test according to the corresponding choice of papers; answer the papers within the prescribed time which is starting from entering the papers; five minutes before the exam is over, the system automatically give students tips to pay attention to the time [8]. As long as it is the examination ending time, if the students themselves have not handed the paper, system will automatically complete the assignment procedure.

In the examination process, if students shut down the answer window due to accident, students can $\log$ in to the system to test again. However, in the examination process, it is not allowed to refresh system through the program has banned the refresh all the way, such as by clicking the refresh because the system has forbidden all the refresh ways through procedures, like clicking the refreshing press button, press F5 or other shortcuts. In addition, other related content will be specifically introduced in 
the module of the examination, exam score at that time will not be preserved, just temporarily providing to students. The test analysis can be viewed after the completion of examination [9].

Answer time: it is determined by the paper setting-up. In the top of the test paper, it is a walking countdown table, to help students to master the time.

Test results: it refers to test scores. List incorrect questions so that candidates can view the questions answered wrongly, and provide the correct answer and analysis of answer so that the candidates can correct. At the end of the exam, the test results are calculated and displayed to the students immediately. Test analysis will list the wrong list of tests, students can see the wrong questions, and gives the error analysis.

Online Q \& A is an online communication between students and students, teachers and teachers or students and teachers. Information exchange requires for rapid and timely updates, and can be discussed by many people. The relevant design of online Q \& A module refers to the way of the online chat rooms. After students and teachers enter the online question answering system, they can speak or discuss about some of the topics. Online Q \& a module process as shown in Figure 3.

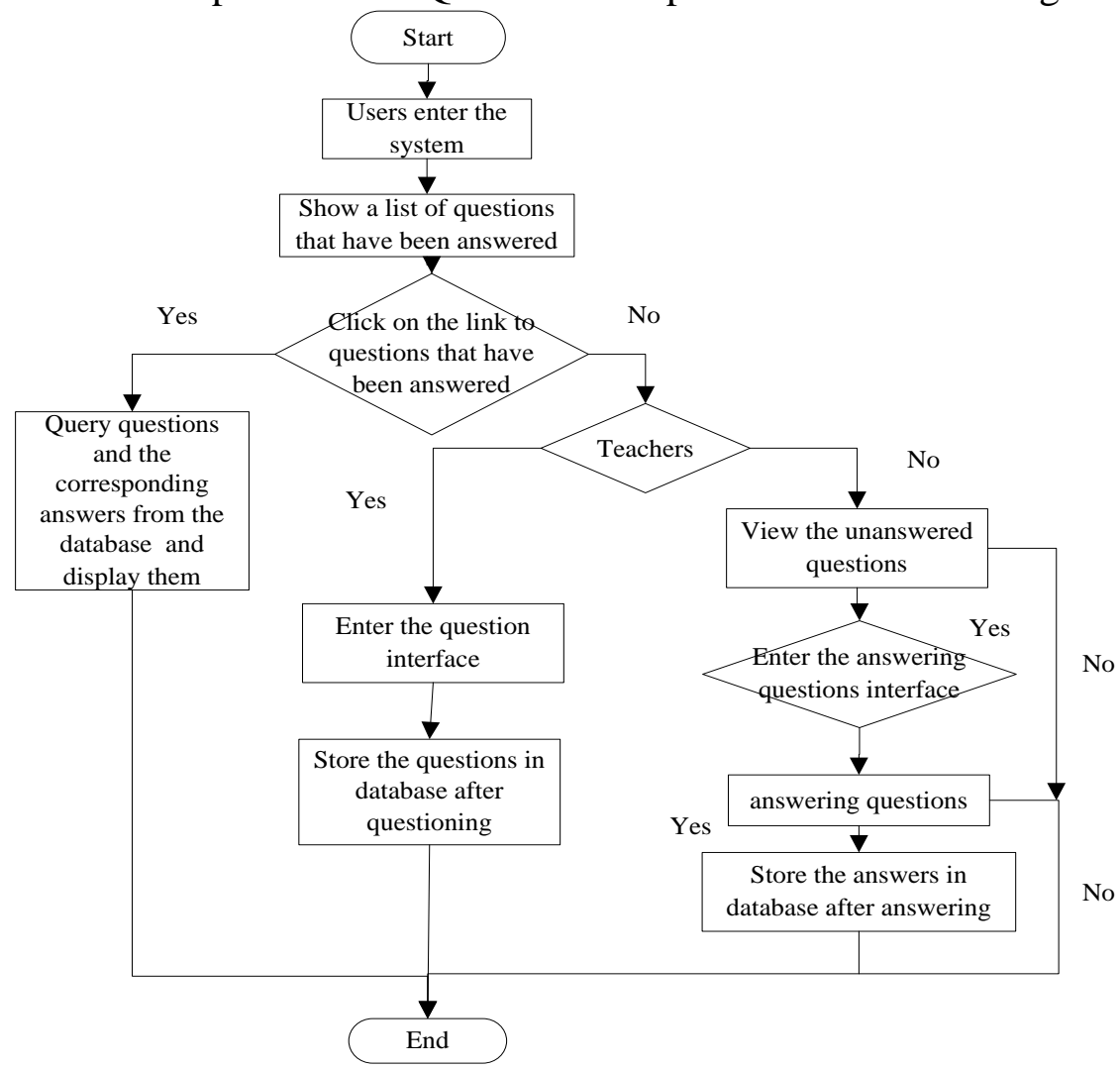

Figure 3 Answering module flow chart

\subsection{Student Field Module}

Student management is mainly the management of users on their own information. Because the general visitors have no personal information, it cannot access this module. It is mainly composed of modifying the user and deleting user these two sub modules.

(1) Modifying user

Modify the user module refers to, based on the user's identity, modify the records in the corresponding database table. Administrators can modify other information in addition to the user name; teachers and students can modify any information, and both of them are required to ensure that the user name modified is unique in the system.

(2) Deleting user

Delete the user is, based on the identity of the user, to decide to delete the teacher users or student users from different database tables. In order to ensure the security of the system, the administrator user cannot be deleted. In addition, according to different user's identity, delete the corresponding record in the student-class table, teacher-class table, teacher curriculum and other database tables. 


\section{Conclusion}

Network teaching system is an emerging application field, which can span the time and space constraints to provide students with a good teaching environment. According to the agricultural teaching practice, this paper studies how the local agricultural Colleges and universities to apply the network technology to achieve assisting teaching. Mainly draw the following conclusions [10].

(1) Because of the limitations of the current traditional sports teaching, taking the characteristics and advantages of the current network teaching as the basis, analyze the advantages of applying network teaching technology to the teaching of agriculture. According to the actual characteristics of the course teaching of agriculture, propose that network technology plays an auxiliary role in the teaching of agriculture.

(2) Establish a system of three layers' structure model, and on this basis, analyze the current popular Web development technology, and determine to take the ASP as the main development technology of the system.

(3) According to the requirement analysis and the overall design of the system, the overall structure of the system is put forward through combining the practical requirements of local agricultural Colleges and universities.

\section{References}

[1] Cooper M, Klymkowsky M. Chemistry, life, the universe, and everything: a new approach to general chemistry, and a model for curriculum reform [J]. Journal of Chemical Education, 2013, 90(9): 1116-1122.

[2] Law W. Globalization and curriculum reform for education for all in China[C] 58th CIES Annual Conference 2014. CIES 2014. 2014.

[3] Milner H R. Scripted and narrowed curriculum reform in urban schools [J]. Urban education, 2013, 48(2): 163-170.

[4] Chen W, Worden M K, Bradley E. Flipping, Engaging, and Teaming. Lessons Learned from a Large Scale Curriculum Reform at a US Medical School[C] 2015 IEEE 15th International Conference on Advanced Learning Technologies. IEEE, 2015: 488-492.

[5] Patil N G, Yip A L M, Ip M S M. Pain and joy in implementation of curriculum reform: The University of Hong Kong Medical Faculty Experience[J]. MGM Journal of Medical Sciences, 2015.

[6] Banks J A. Approaches to multicultural curriculum reform. Trotter Review, 3 (3): Article 5[J]. 2015.

[7] Vanderlinde R, van Braak J, Dexter S. ICT policy planning in a context of curriculum reform: Disentanglement of ICT policy domains and artifacts [J]. Computers \& Education, 2012, 58(4): 1339-1350.

[8] Shu-qing L I N. Higher School Computer Network Curriculum Teaching Reform Practice [J]. Computer Knowledge and Technology, 2013, 8: 038.

[9] Zhi G C, Ya L Z. An inquiry-based blended learning system for computer network curriculum[C] Computer Science \& Education (ICCSE), 2013 8th International Conference on. IEEE, 2013: 1340-1345.

[10] Aldrich P R. The curriculum prerequisite network: Modeling the curriculum as a complex system [J]. Biochemistry and Molecular Biology Education, 2015, 43(3): 168-180. 